\title{
The Effect of Cold Swaging of Tungsten Heavy Alloy with the Composition W91-6Ni-3Co on the Mechanical Properties
}

\author{
Paweł Skoczylas $\left(\mathbb{D}\right.$, Olgierd Goroch * ${ }^{\mathbb{D}}$, Zbigniew Gulbinowicz $(\mathbb{D}$ and Andrzej Penkul \\ Department of Mechanics and Weaponry Technology, Faculty of Mechanical and Industrial Engineering, \\ Warsaw University of Technology, Narbutta 85, 02-524 Warsaw, Poland; pawel.skoczylas@pw.edu.pl (P.S.); \\ zbigniew.gulbinowicz@pw.edu.pl (Z.G.); andrzej.penkul@pw.edu.pl (A.P.) \\ * Correspondence: olgierd.goroch@pw.edu.pl
}

Citation: Skoczylas, P.; Goroch, O.; Gulbinowicz, Z.; Penkul, A. The Effect of Cold Swaging of Tungsten Heavy Alloy with the Composition W91-6Ni-3Co on the Mechanical Properties. Materials 2021, 14, 7300. https://doi.org/10.3390/ma14237300

Academic Editors: Yong Chae Lim and Daniela Kovacheva

Received: 11 November 2021 Accepted: 25 November 2021 Published: 29 November 2021

Publisher's Note: MDPI stays neutral with regard to jurisdictional claims in published maps and institutional affiliations.

Copyright: (c) 2021 by the authors. Licensee MDPI, Basel, Switzerland. This article is an open access article distributed under the terms and conditions of the Creative Commons Attribution (CC BY) license (https:/ / creativecommons.org/licenses/by/ $4.0 /)$.

\begin{abstract}
The paper presents the results of studies on the effects of heat treatment and cold-work parameters on the mechanical properties and microstructure of the tungsten heavy alloy (WHA) with the composition W91-6Ni-3Co. Tungsten heavy alloy (WHA) is used in conditions where strength, high density, and weight are required. The material for testing as rod-shaped samples was produced by the method of powder metallurgy and sintering with the participation of the liquid phase and then subjected to heat treatment and cold swaging. The study compares the effect of degree deformation on the strength, hardness, microhardness, and microstructure of WHA rods. The conducted tests showed that heat treatment and cold-work allowed to gradually increase the strength parameters, i.e., tensile strength $\sigma_{u t s}$, yield strength $\sigma_{y s}$, elongation $\varepsilon$, hardness, and microhardness. These processes made it possible to increase the tensile strength by over $800 \mathrm{MPa}$ (from the initial $600 \mathrm{MPa}$ after sintering to the final value of over $1470 \mathrm{MPa}$ after heat treatment with cold swaging deformation with reduction of $30 \%$ ) and the hardness from 32 to $46 \mathrm{HRC}$.
\end{abstract}

Keywords: tungsten heavy alloys; liquid phase sintering; mechanical properties; kinetic energy penetrator

\section{Introduction}

Tungsten heavy alloys (WHA) are high-density materials combined with high strength, plasticity, and toughness. WHA is used in various industries. Most commonly, WHA is used in applications requiring counterweights, inertial masses, radiation shielding, and ordnance products, as well as a number of other applications [1,2]. Due to the very high melting point, these alloys are usually made from a mixture of powders, which are sintered at a liquid phase $[3,4]$ at about $1520{ }^{\circ} \mathrm{C}$ after compaction. At this temperature, nickel and cobalt melt and combine with tungsten grains. After sintering, the material can be described as a two-phase composite consisting of spherical tungsten grains embedded in a bonding phase that is a $\mathrm{Ni} / \mathrm{Co} / \mathrm{W}$ alloy [5-13].

WHA rods obtained after the sintering process involving the liquid phase and additional vacuum heat treatment (dehydrating) are characterized by the following physical properties: tensile strength $\sigma_{u t s}=800-1100 \mathrm{MPa}$, yield strength $\sigma_{y s}=750-800 \mathrm{MPa}$, elongation $\varepsilon=20-35 \%$, and HRC hardness 26-32 [14,15]. Tungsten heavy alloy is used in conditions where strength, high density, and weight are required. In this section, it is discussed in detail where and why tungsten heavy alloy (WHA) is used. For some applications (especially military), the strength of such materials is too low. For many years, the investigations have been carried out in the world to increase the penetrating capabilities of kinetic energy projectiles. The depth of penetration for such projectiles depends most of all on the dynamic hardness and the density of projectile's material, unit mass of the projectile, and on the hit velocity. In order to obtain possibly high values, the penetrators are usually made from: tungsten heavy alloys (WHA) with density $\rho \approx 17,500 \mathrm{~kg} / \mathrm{m}^{3}$ and depleted uranium DU with density $\rho \approx 19,000 \mathrm{~kg} / \mathrm{m}^{3}[16,17]$. 
APFSDS (armor-piercing fin stabilized discarding sabot) ammunition developed at the end of the sixties for smooth bore guns was a breakthrough in questions referring to the tank armor penetration depth. A significant increase in armor penetration depth (against the projectiles of former generation) was provided by the possibilities for reaching muzzle velocities up to $1800 \mathrm{~m} / \mathrm{s}$ for the smooth gun APFSDS projectiles and for obtaining the penetrator's slenderness $(\mathrm{L} / \mathrm{d})$ above 10 . The steel with high mechanical performance was used first for the penetrators. In the next step, APFSDS projectiles with carbide-tungsten cores were developed. The development of sintering technology (deployment of such additives as nickel, iron, cobalt, copper, and rhenium) and the mechanical processing of tungsten sinters (e.g., perimeter swaging) made the slenderness of the penetrator increase from 10 to over 30 [18-21].

Recent research on tungsten heavy alloys used for subcaliber bullet cores has focused on increasing their effectiveness, as measured by the thickness of the armor pierced by them. Such actions increase strength while maintaining the highest possible density [16-21]. The desire to increase the strength properties while maintaining the possible high density, which, depending on the tungsten content in the alloy, has a negative impact on the resistance to dynamic loads. In this work, the findings of measurements of the hardness and microhardnesses of tungsten grains and matrix were described in the cross-sections of the rod, depending on the swaging deformation of cold-work processing.

\section{Materials and Methods}

Liquid-phase sintering is a sintering in which the liquid phase coexists with the solidphase particles. This method makes it possible to obtain material with a density close to or almost equal to the theoretical density. The liquid phase is formed during sintering as a result of the eutectic reaction of the metals used as additives with tungsten. Nickel, used as the basic alloy component forming the binding phase (matrix) of WHA alloys, lowers the sintering temperature and ensures the good wettability of tungsten grains and its solubility in the liquid phase. The other ingredients, i.e., $\mathrm{Fe}, \mathrm{Cu}, \mathrm{Co}$, and others, function to lower the sintering temperature, reduce the solubility of tungsten in nickel, improve the mechanical properties of the matrix, and increase the strength at the interface between the tungsten grain and the matrix phase [22]. In order to reduce the oxides, the sintering process is carried out under a hydrogen atmosphere. A heavy tungsten alloy with the composition $91 \%$ wt $\mathrm{W}, 6 \% \mathrm{wt} \mathrm{Ni}, 3 \% \mathrm{wt}$ Co was chosen as a base alloy, to evaluate the effect of post sintering mechanical treatment, on the mechanical and structure properties of this alloy. The characteristics of the elemental powders are given in Table 1, and the morphologies of the different powders are illustrated in Figure 1.

Table 1. Characteristics of the elemental powders.

\begin{tabular}{cccc}
\hline Powder & W & Ni & Co \\
\hline Shape & polygonal & sponge & nearly spherical \\
\hline Particle size $(\mu \mathrm{m})$ & $1-4$ & $3-7$ & $5.0-6.5$ \\
\hline App density $\left(\mathrm{g} / \mathrm{cm}^{3}\right)$ & 4.3 & $1.6-2.6$ & $0.8-1$ \\
\hline Melting temperature $\left({ }^{\circ} \mathrm{C}\right)$ & 3422 & 1455 & 1495 \\
\hline Density $\left(\mathrm{g} / \mathrm{cm}^{3}\right)$ & 19.3 & 8.9 & 8.9 \\
\hline
\end{tabular}

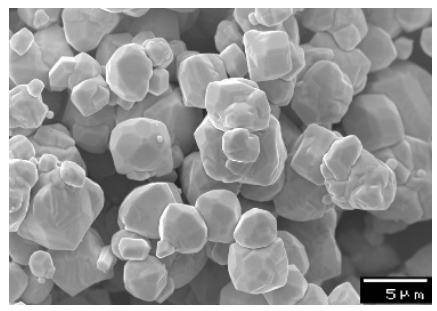

(a)

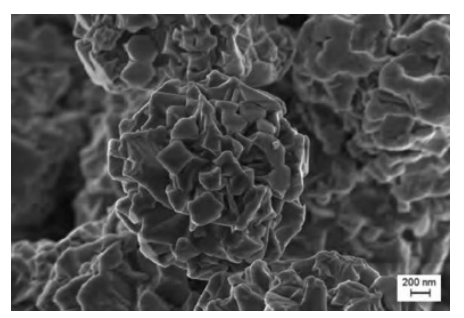

(b)

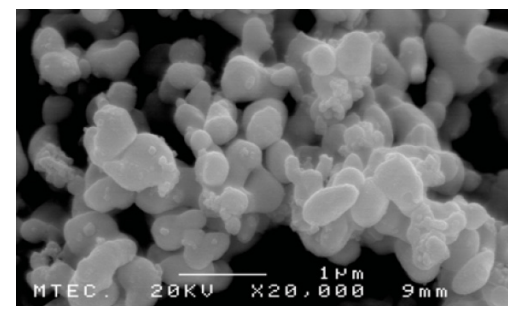

(c)

Figure 1. The morphology of the used powders. (a) Tungsten, (b) nickel, (c) cobalt. 
The first step in the production of tungsten heavy alloys was to mix the appropriate amount of powders to homogenize the blends in a drum mixer. For the selected chemical composition of WHA, the theoretical density was $17.46 \mathrm{~g} / \mathrm{cm}^{3}$. The mixing time was based on previous studies $[23,24]$ and was $20 \mathrm{~h}$. The next stage was pressing in a steel die, into which about $7 \mathrm{~kg}$ of the powder mixture was poured each time. Pressing was carried out on a Voeller angle press under a pressure of $200 \mathrm{MPa}$. Rod-shaped moldings with a diameter of approximately $42 \mathrm{~mm}$ and a length of $510 \mathrm{~mm}$ were obtained. After the moldings were placed on the $\mathrm{Al}_{2} \mathrm{O}_{3}$ ballast on a molybdenum tray, they were placed in a Vacuum Industries chamber furnace. Sintering was carried out in a hydrogen atmosphere according to the assumed cycle (Figure 2). The sintering with the liquid phase took place for about $20 \mathrm{~min}$ at the temperature of $1520^{\circ} \mathrm{C}$ with the liquid phase [25].

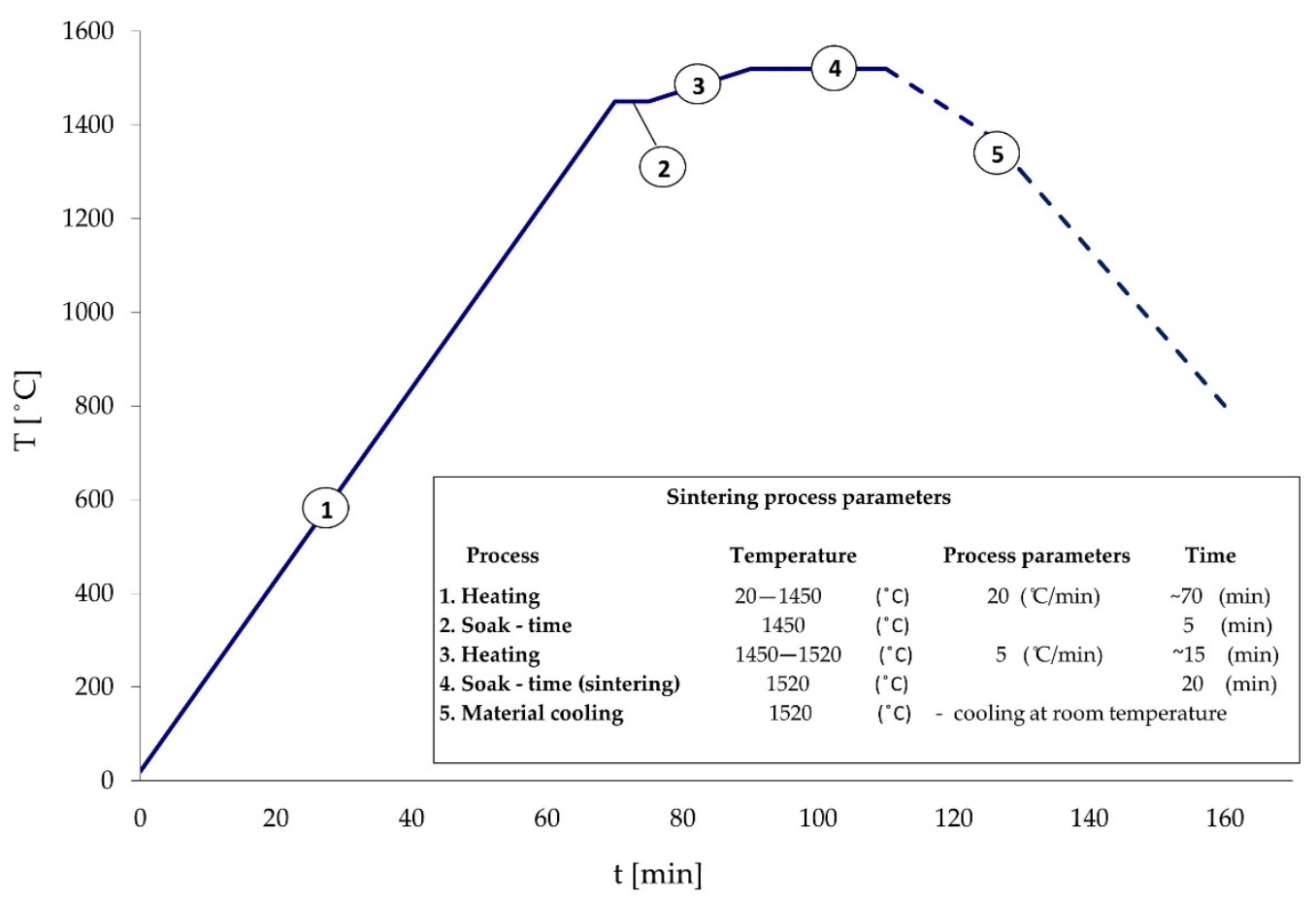

Figure 2. Sintering temperature diagram.

After sintering, the rods were heat-treated. The aim was to make the alloy ductile so that it could be cold-worked. The heat treatment was carried out in a vacuum furnace under a reduced pressure of $5 \mathrm{~Pa}$ in the temperature range of $950-1150{ }^{\circ} \mathrm{C}$. After annealing, the total time of which was $9 \mathrm{~h}$, and the rods were cooled rapidly [26]. The annealing temperature and time were selected based on previous tests [27-30].

In the next stage of the manufacturing process, the WHA rods were cold-worked. Before the swaging process, the rods were machined. The aim was to ensure uniform cold swaging deformation on the rod cross-section. The cold swaging deformations of the rods [31,32] was carried out on a STEYER SPH06.09 four-lever swaging machine with reductions in the range of $15-30 \%$. The following values of swaging deformation were obtained in the range: $15 \%$ in one pass and $20-30 \%$ in two passes.

The deformation of the material takes place in the oscillating swaging machines in the plane passing through the rod axis (Figure 3). Lever-attached dies obtain the oscillatory motion of the eccentrics. This results in a sinusoidal approximation of the speed of moving the die working. The opposite arrangement of the dies internally balances the system of forces so that the swaging machine does not transfer loads to the foundation. Cold swaging may be carried out either simultaneously with four dies or by alternating the counter-rotating dies in pairs. 


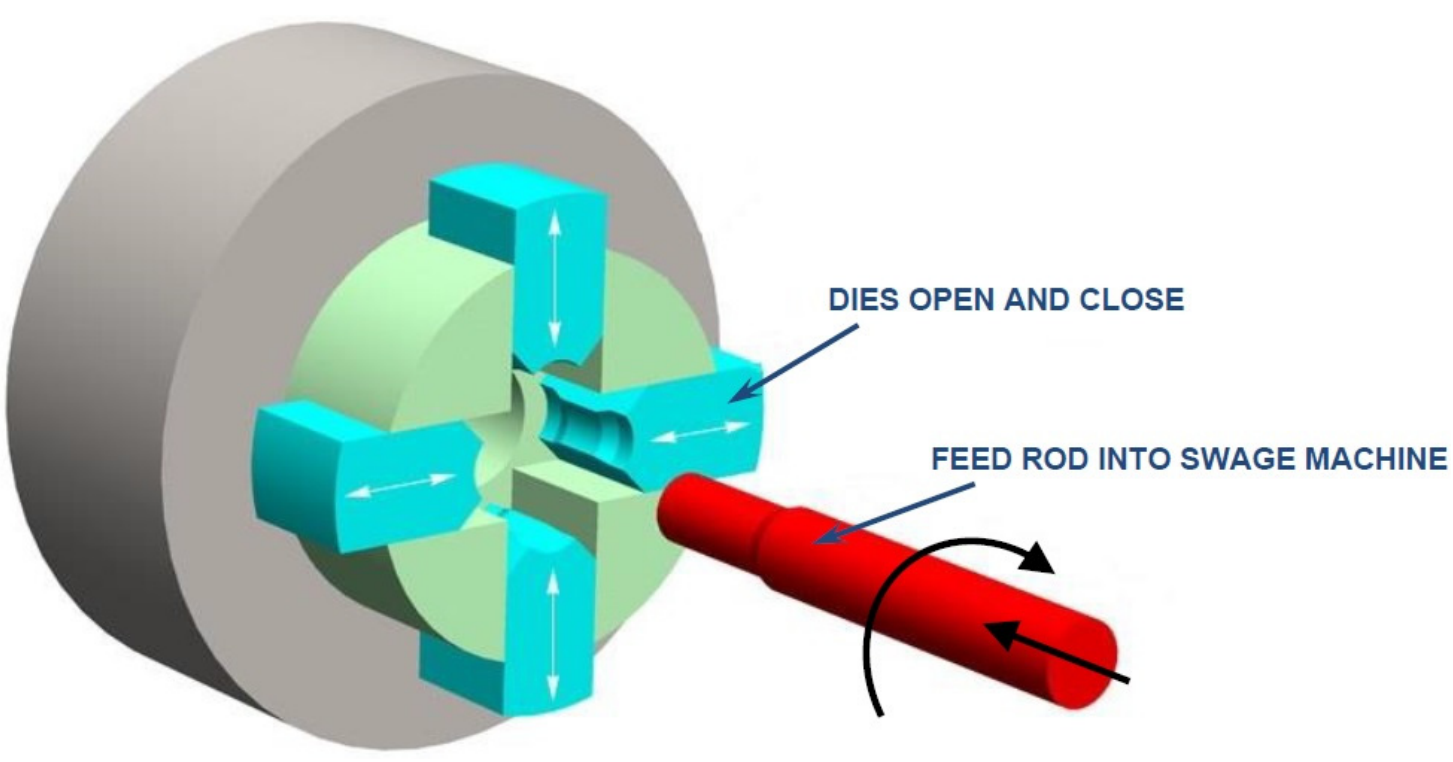

Figure 3. Graphic illustration of the tungsten heavy alloys cold swaging process.

The deformation process is stable when the friction angle is greater than the tangent of half the angle of inclination $\beta$ of working surfaces.

The dies for swaging heavy tungsten alloys are made of NC10 steel. These dies have a converging crushing zone (Lz length) at an angle of $12^{\circ}$ and a calibration segment (Lk length) measured along the die axis (Figure 4).
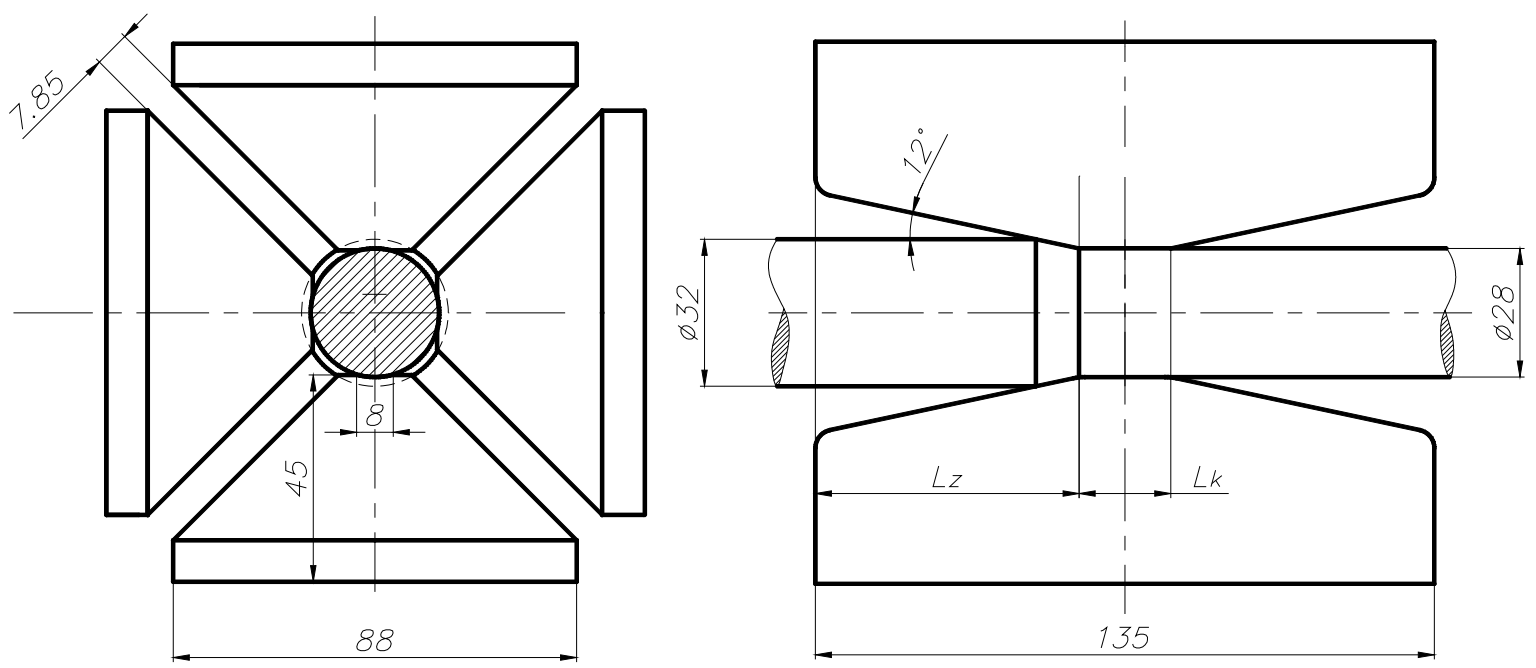

Figure 4. Diagram of the rod cold swaging process.

The rods were swaged at the following parameters: feed $1.5 \mathrm{~mm} / \mathrm{s}$ and revolutions $30 \mathrm{rpm}$ (Figure 5). The rods were swaged at two aisles. The cold swaging deformation was calculated from the formula:

$$
\text { deformation value }=\frac{(\text { outer diameter })^{2}-(\text { inner diameter })^{2}}{(\text { outer diameter })^{2}} \times 100 \%
$$




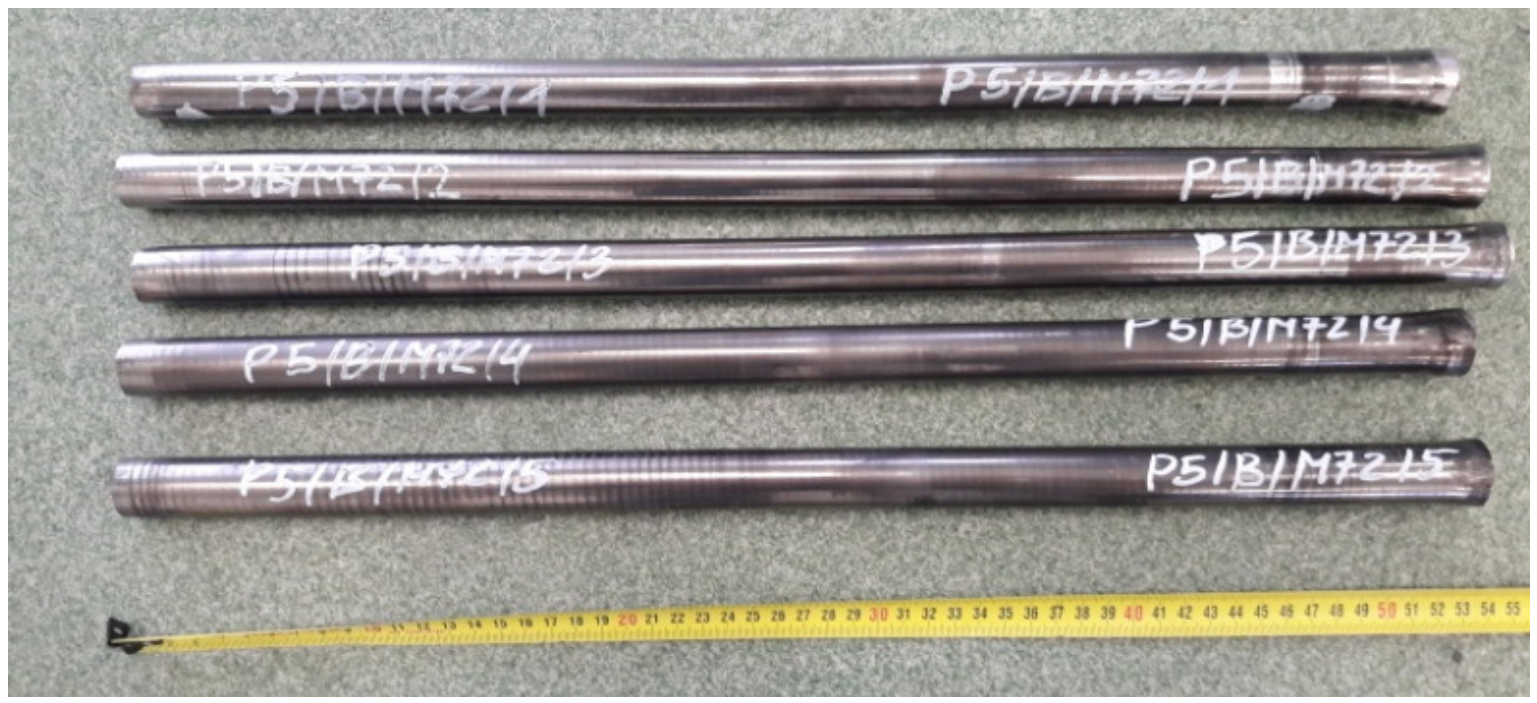

Figure 5. View of rods samples (WHA) after cold swaging.

The length of the swaged rods was 520-540 $\mathrm{mm}$, and the diameter was $26-29 \mathrm{~mm}$. The results obtained depended of the cold swaging deformation value and the initial length of the rod. Hardness, microhardness, and microstructure observations were performed for the materials thus obtained, and tests of mechanical properties were carried out using a static tensile test $[33,34]$. The aim of the static tensile test was to determine: tensile strength $\sigma_{u t s}$, yield strength $\sigma_{y s}$, elongation $\varepsilon$. The tests were carried out on 5-fold round samples with machining in the axis of the rod with a nominal measuring diameter of $5 \mathrm{~mm}$ (Figure 6). The test samples were prepared in accordance with the PN-EU 10002-1:2004 standard. The tensile test was carried out on an INSTRON model 1115 with a strain rate of $6.6 \times 10^{-4} \mathrm{~s}^{-1}$.

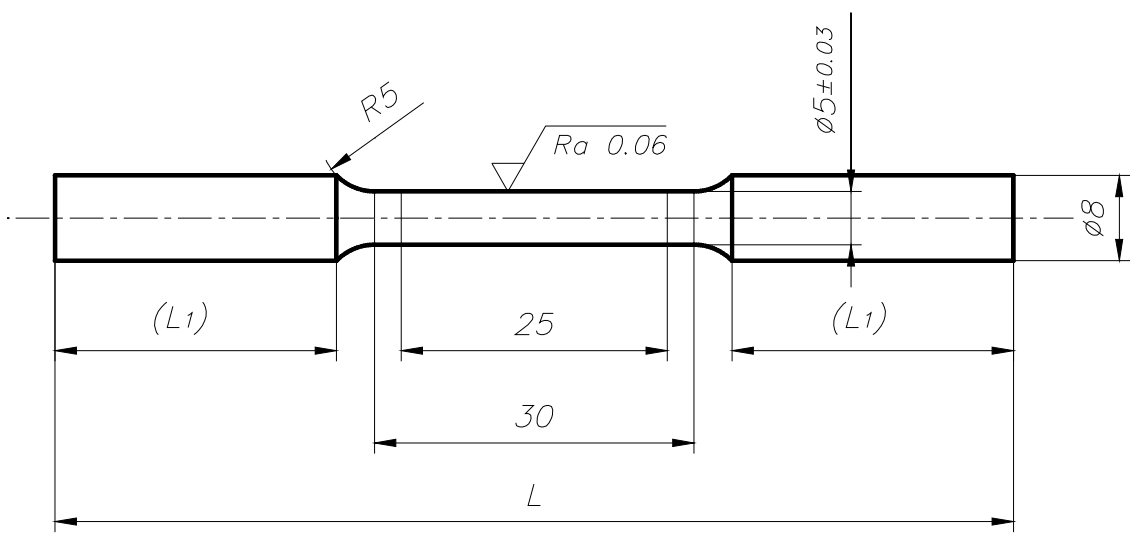

Figure 6. Dimensions (in $\mathrm{mm}$ ) of samples intended for mechanical tensile tests ( $\mathrm{L}-\sim 95 \mathrm{~mm}$, $\mathrm{L}_{1}$ 30 $\mathrm{mm}$ ).

Observations on the metallographic microscope were carried out perpendicular and parallel to the axis of the rod. The observations of the microstructure were carried out on the Nikon Eclipse MA-200 Microscope (Nikon Corporation, Tokyo, Japan). The metallographic microsections of the rod sections were made by hot-mounting. The metallographic samples were ground on $\mathrm{SiC}$ sandpaper in the gradation range 320-1200 and then polished with a diamond suspension. Grinding and polishing of the samples were performed on a Shapir 520 semiautomatic grinder-polisher. The hardness and microhardness tests were carried out on transverse microsections. The measurement was carried out in the middle part of the sample to reflect the place where strength samples were taken. Microhardness studies were conducted on the microhardness tester machine (Future-Tech FM 810, Future-Tech Corp. Tokyo, Japan) under a load of $25 \mathrm{~g}$ and a dwell time of $15 \mathrm{~s}$. Spacing was about 
4 diagonals of the microindenter. The average obtained value was based on a sample of 20-25 measurements in a given area. The hardness test was performed with a standard load on an HRC hardness tester machine (HR-150A, Jinan Hensgrand Instrument Co., LTD., Jinan, China).

\section{Results}

\subsection{Test Results in a Static Tensile Test}

The test specimens were prepared according to Figure 6 and taken from the rod axis at a distance of about $100 \mathrm{~mm}$ from the edge. The static tensile test was carried out with a strain rate of $6.6 \times 10^{-4} \mathrm{~s}^{-1}$. The results of the tests of mechanical properties are presented below in tabular form (Table 2) and in the graphs (Figures 7 and 8).

Table 2. WHA mechanical properties test results.

\begin{tabular}{cccc}
\hline Condition of Alloy & $\begin{array}{c}\text { Tensile Strength } \sigma_{u t s} \\
\text { [MPa] }\end{array}$ & $\begin{array}{c}\text { Proof Stress } \\
\sigma_{y s} \text { [MPa] }\end{array}$ & $\begin{array}{c}\text { Elongation } \\
\varepsilon[\%]\end{array}$ \\
\hline After sintering & $622 \pm 6$ & did not occur & 0 \\
\hline After heat treatment & $1159 \pm 4$ & $747 \pm 5$ & $33.8 \pm 0.9$ \\
\hline Cold swaging reduction 15\% & $1313 \pm 5$ & $1263 \pm 5$ & $16.5 \pm 1.1$ \\
\hline Cold swaging reduction 20\% & $1380 \pm 6$ & $1342 \pm 17$ & $11.0 \pm 1.4$ \\
\hline Cold swaging reduction $25 \%$ & $1428 \pm 4$ & $1386 \pm 8$ & $10.1 \pm 1.3$ \\
\hline Cold swaging reduction $30 \%$ & $1464 \pm 13$ & $1430 \pm 18$ & $8.6 \pm 1.4$ \\
\hline
\end{tabular}

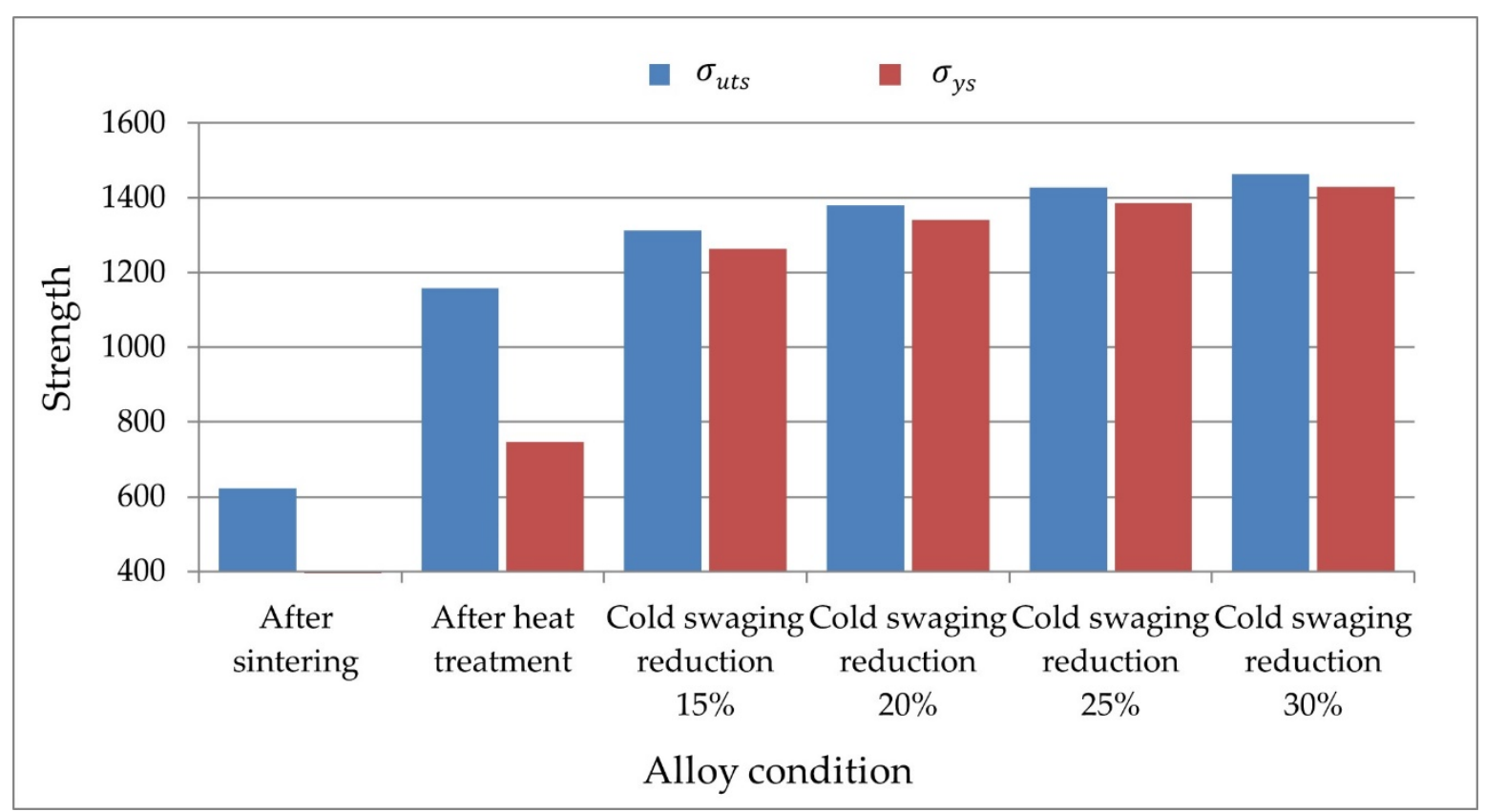

Figure 7. The results of tests of tensile strength $\sigma_{u t s}$ and proof stress $\sigma_{y s}$. 


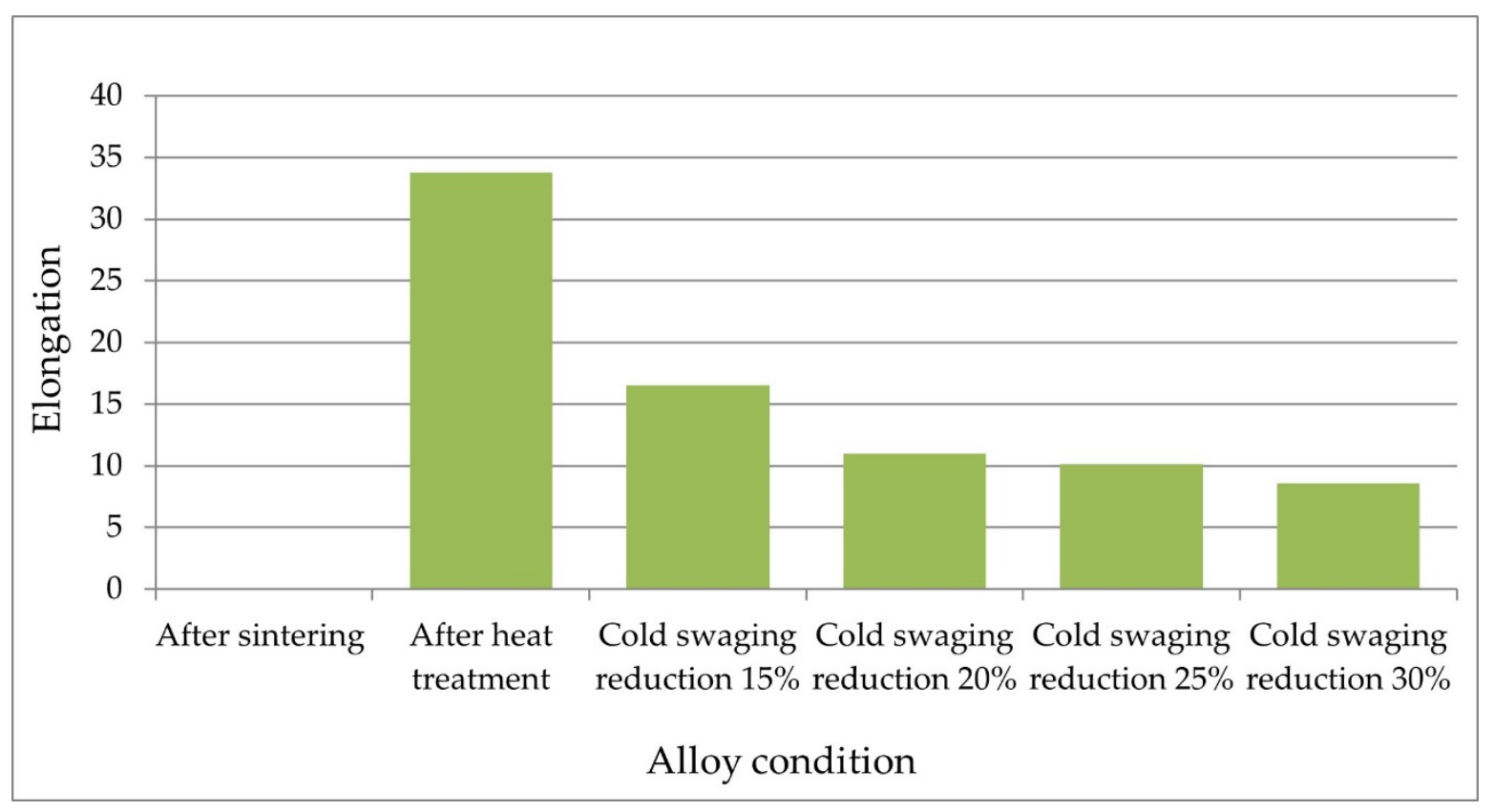

Figure 8. Elongation test results.

The material is brittle immediately after sintering. The samples are broken in the elastic range. The obtained tensile strength is $622 \mathrm{MPa}$. The use of heat treatment increases the tensile strength to $1150 \mathrm{MPa}$, the proof strength to $750 \mathrm{MPa}$, and the elongation to $34 \%$. The heat treatment and the cold swaging process strengthens the material in the following values:

For cold swaged with a reduction of $15 \%$, the tensile strength increases to $1313 \mathrm{MPa}$, the yield point increases to $1263 \mathrm{MPa}$, and the elongation decreases to $16.5 \%$.

The increase in the reduction of cold swaged deformation to $20 \%$ increased the strength by $68 \mathrm{MPa}$ to the value $1380 \mathrm{MPa}$, the yield strength by $25 \mathrm{MPa}$ to the value $1268 \mathrm{MPa}$, and the decrease in elongation by $5 \%$ to the value $11 \%$.

The increase in the reduction of cold swaged deformation to $25 \%$ causes a further increase in the strength to the value of $1428 \mathrm{MPa}$, the yield strength to $1386 \mathrm{MPa}$, and the decrease in elongation to $10 \%$.

For the highest reduction of cold swaged $30 \%$, the highest strength parameters were obtained: $\sigma_{u t s}=1464 \mathrm{MPa}, \sigma_{y s}=1430 \mathrm{MPa}$, and the lowest elongation value $\varepsilon=8.6 \%$.

\subsection{Analysis of the Microstructure}

Figure 9 contains metallographic [35] photographs showing the microstructure of 91WNi6Co3 alloy: after sintering (a), after heat treatment (b), and after cold swaging deformation with reduction of $15 \%$ (c), $20 \%$ (d), 25\% (e), and 30\% (f). After heat treatment [36] in the matrix, during the observation of the microstructure, small separations are visible, invisible in the matrix after sintering. In the microstructure of the alloy, after cold swaging (Figure $9 b$ ), tungsten grains are visible, deformed plastically along the direction of swaging. 


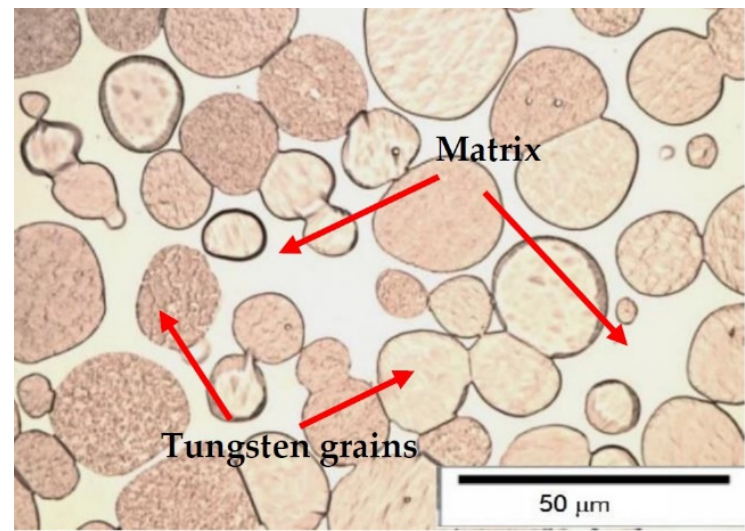

(a)

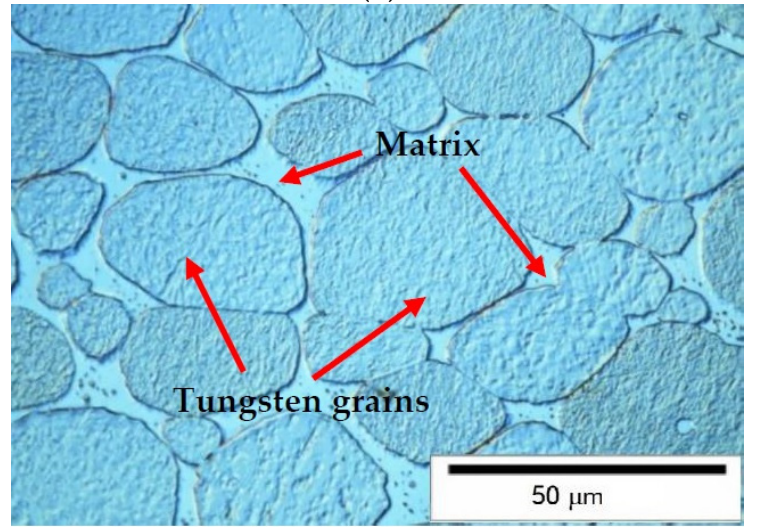

(c)

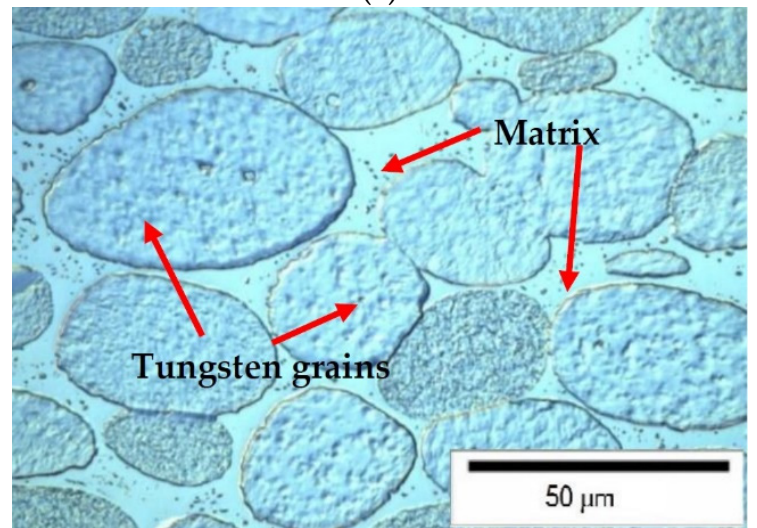

(e)

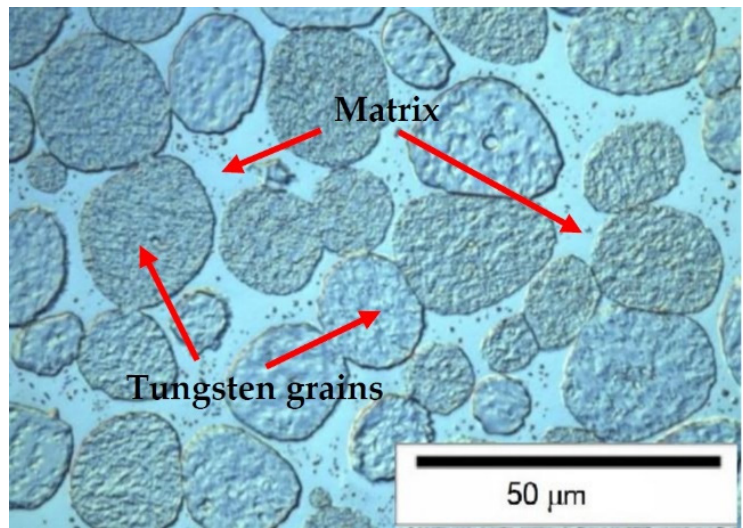

(b)

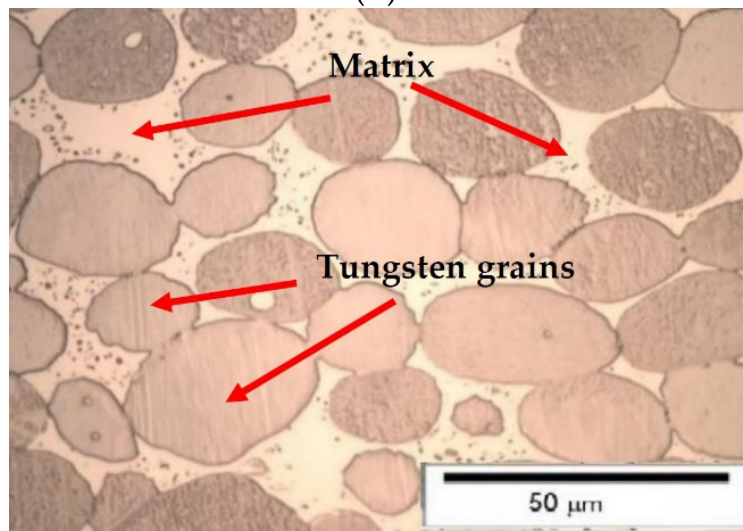

(d)

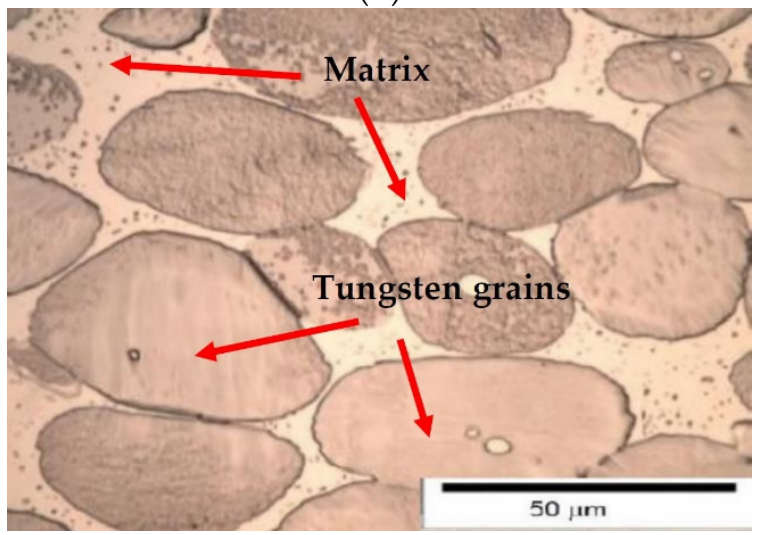

(f)

Figure 9. Microstructure of PR200 alloy after sintering (a), after heat treatment (b), and after cold swaging deformation with reduction of: $15 \%(\mathbf{c}), 20 \%(\mathbf{d}), 25 \%(\mathbf{e})$, and $30 \%(\mathbf{f})$.

As a result of observation of metallographic samples after sintering and heat treatment, it can be concluded that the rods are homogeneous throughout the cross-section [37]. Tungsten grains in the microstructure are correctly formed, and no pores or discontinuities were observed.

\subsection{Microhardness Test Results}

The investigated material is two-phase. It consists of tungsten grains and a $\mathrm{W} / \mathrm{Ni} / \mathrm{Co}$ matrix. For this reason, the microhardness of tungsten grains and matrix was tested separately.

Table 3 and Figures 10 and 11 show the results of measurements of hardness and microhardness of rods after heat treatment (input condition) and rods for various deformation degrees of cold swaging. Figure 12 shows the method of taking the imprints of the micro-indenter in the matrix and of the tungsten grains. 
Table 3. Results of measurements of microhardness HV 0.025 and hardness HRC.

\begin{tabular}{cccc}
\hline Machining Status & $\begin{array}{c}\text { Matrix } \\
\text { [HV 0.025] }\end{array}$ & $\begin{array}{c}\text { Tungsten Grain } \\
\text { [HV 0.025] }\end{array}$ & $\begin{array}{c}\text { Hardness } \\
\text { [HRC] }\end{array}$ \\
\hline After sintering & $418 \pm 21$ & $430 \pm 16$ & 32 \\
\hline After heat treatment & $440 \pm 14$ & $462 \pm 18$ & 34 \\
\hline Cold swaging reduction (15\%) & $505 \pm 28$ & $516 \pm 24$ & 43 \\
\hline Cold swaging reduction (20\%) & $547 \pm 26$ & $527 \pm 17$ & 45 \\
\hline Cold swaging reduction (25\%) & $560 \pm 27$ & $546 \pm 23$ & 45 \\
\hline Cold swaging reduction (30\%) & $574 \pm 29$ & $563 \pm 18$ & 46 \\
\hline
\end{tabular}

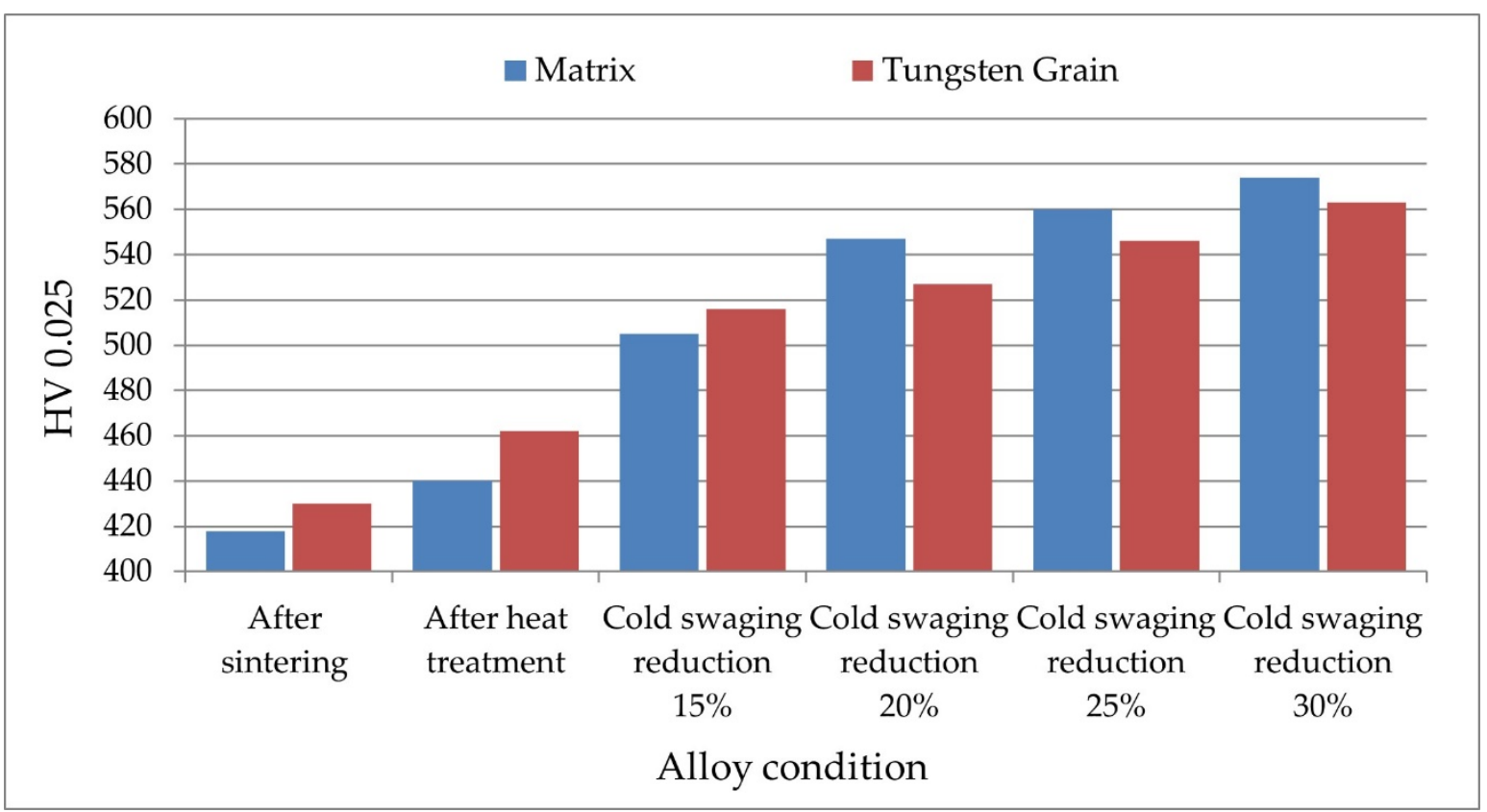

Figure 10. The results of microhardness HV0.025 of tungsten grains and matrix measured along the rod axis.

The results of the studies on the effect of the degree of cold swaging deformation on the strength parameters were presented at work [25]. The current work focuses on examining the effect of the degree of swaging on the microhardening on the WHA and on determining the differences in the microhardness of tungsten grains and matrix. This determines the minimum value of the cold swaging deformation degree, ensuring a homogeneous hardening of the microstructure components, with a known rod diameter.

The presented test results show that the applied machining cycle (heat treatment, then swagging the material according to a different value of deformation) causes a gradual increase in the hardness and microhardness of the alloy. The microhardness of tungsten grains in the material immediately after sintering is $430 \mathrm{HV} 0.025$, while the matrix is 418 HV0.025.

Heat treatment increases the microhardness of tungsten grains and matrix by 20-30 HV0.025 units (tungsten grains 460 HV0.025 and matrix 440 HV0.025). 


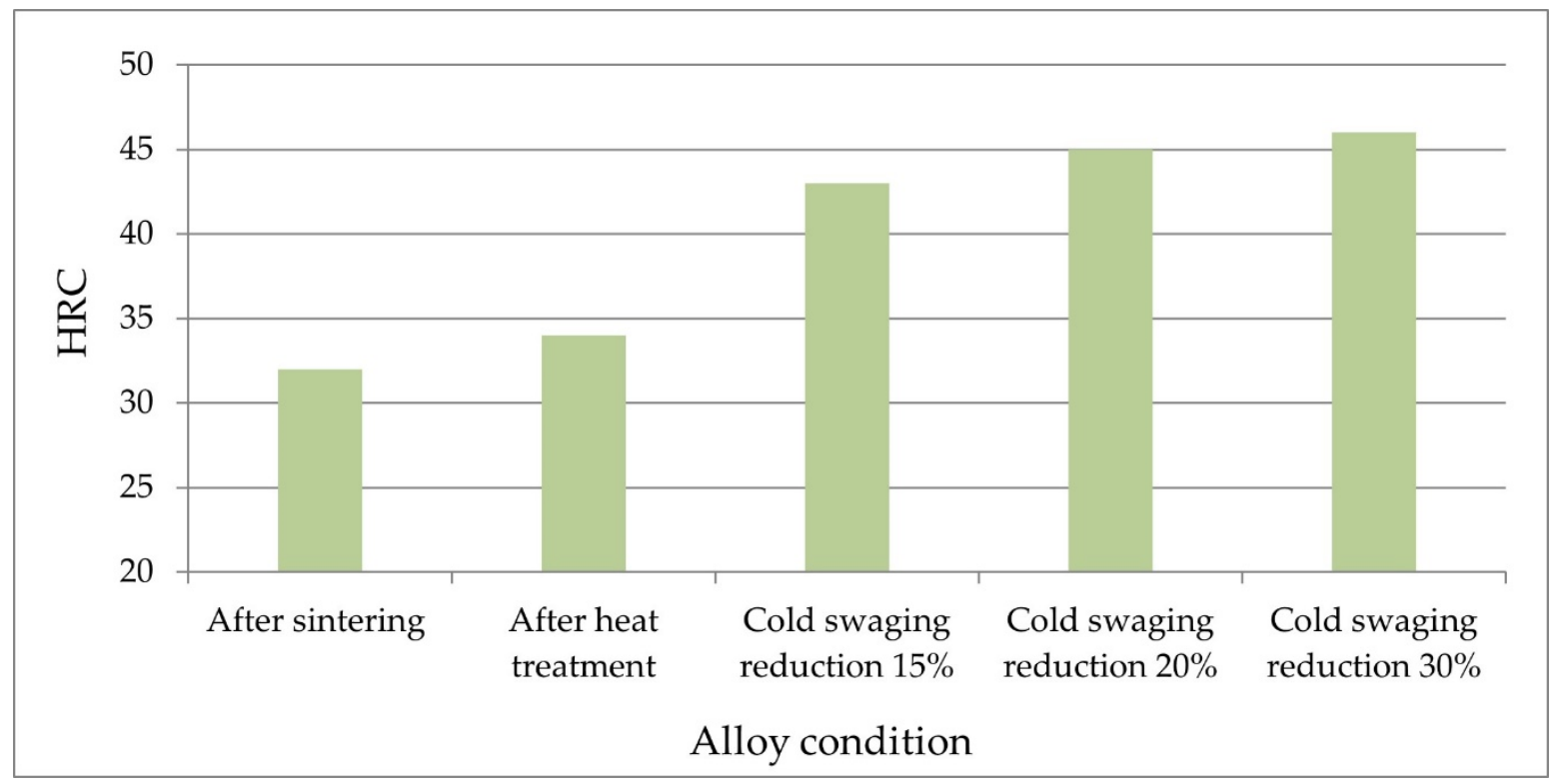

Figure 11. The results of the HRC hardness of the tungsten grains and the matrix measured along the bar axis.

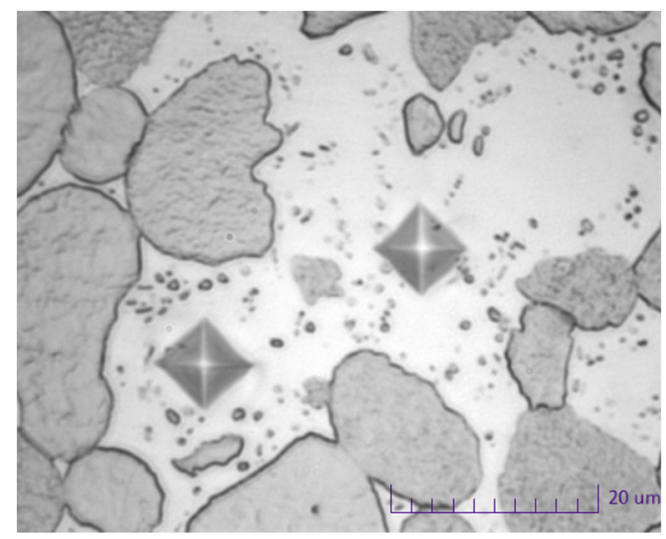

(a)

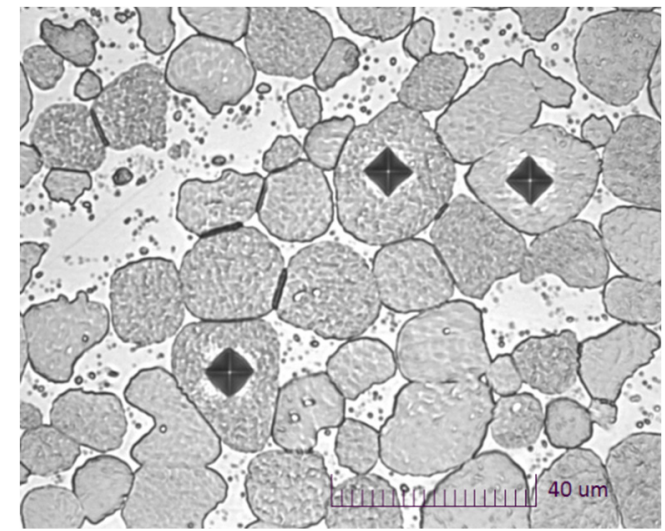

(b)

Figure 12. View of indenter imprints in the matrix and tungsten grains (with lens magnification: $(\mathbf{a})-\times 100,(\mathbf{b})-\times 50)$.

Cold swaged with a reduction of $15 \%$ [38] increases the microhardness by about 60-70 HV0.025 units in relation to the condition after hot treatment. The microhardness of tungsten grains is $516 \mathrm{HV} 0.025$ units, and of matrix, 505 HV0.025 units. For a higher value of reductions $(20 \%, 25 \%$, and $30 \%)$, the microhardness of the matrix is higher than the microhardness of tungsten grains. Increasing the deformation value in cold swaging to $20 \%$ causes a greater strengthening of the matrix than of tungsten grains. The matrix microhardness is $547 \mathrm{HV} 0.025$ (increase by 40 units in relation to the cold swaging deformation value of $15 \%$ ). The microhardness of tungsten grains is $527 \mathrm{HV} 0.025$ (an increase of $10 \mathrm{HV}$ 0.025 units compared to the previous state). Cold swaged with a reduction of $25 \%$ causes further strengthening of the matrix and tungsten grains. The degree of microhardness increase for tungsten grains is higher than the degree of strengthening the matrix. The matrix microhardness is $560 \mathrm{HV} 0.025$ (increase by 13 units in relation to the cold swaging deformation value of $20 \%$ ). Microhardness of tungsten grains is $546 \mathrm{HV} 0.025$ (increase by $20 \mathrm{HV} 0.025$ units in relation to the cold swaging deformation value of $20 \%$ ). Cold swaged with a reduction of $30 \%$ in relation to the $25 \%$ increases the matrix microhardness by a further $14 \mathrm{HV} 0.025$ units and amounts to $574 \mathrm{HV} 0.025$. The microhardness of tungsten grains in the rod axis for cold swaging reduction of $30 \%$ is higher by 17 units (with reference to 
$25 \%$ ) and amounts to $563 \mathrm{HV} 0.025$. The presented results show that for reduction value of $20 \%$ and $30 \%$, the matrix strengthening is higher than the hardening of the tungsten grains.

The results of the Rockwell hardness measurements show that the initial hardness after sintering is $32 \mathrm{HRC}$. After heat treatment, it is increased to $34 \mathrm{HRC}$. The greatest increase in hardness occurs at the initial cold swaging with reduction $15 \%$ and amounts to 43 HRC. Further swaging the material allows one to obtain a hardness of $45-46 \mathrm{HRC}$. The same as for HRC microhardness increases after heat treatment and with increasing degree of swagging. However, it reaches maximum values with a swaging deformation of about $30 \%$. Above this value, the hardness does not change.

\section{Discussion}

The measurements of the alloy $[39,40]$ composition 91W-6NI-3Co after the sintering process showed that the real alloy density is equal to the theoretical alloy density $\left(\rho=17.46 \mathrm{~g} / \mathrm{cm}^{3}\right)$. This means that the alloy produced by powder metallurgy and sintering with the participation of the liquid phase is a nonporous material. This is evidenced by the analysis of the microstructure of the metallographic specimens longitudinal and transverse to the axis of the sintered rod. It showed that the quality of the material was obtained, in which no material defects in the volume of the material in the form of pores, microshrinkage, or voids were found. The metallographic analysis also showed that the alloy microstructure shows the correct two-phase structure consisting of ellipsoidal tungsten grains in the matrix of the binding phase.

The applied heat treatment causes precipitations in the area of the binding phase of the alloy, with probably intermetallic phases with an increased tungsten content. Precipitations in the area of the binding phase (supersaturation) are probably one of the main reasons for the increase in strength and microhardness of the matrix after heat treatment.

The diagram (Figure 13) shows the difference in the increase in tensile strength both from the initial state (after sintering) and from the previous state.

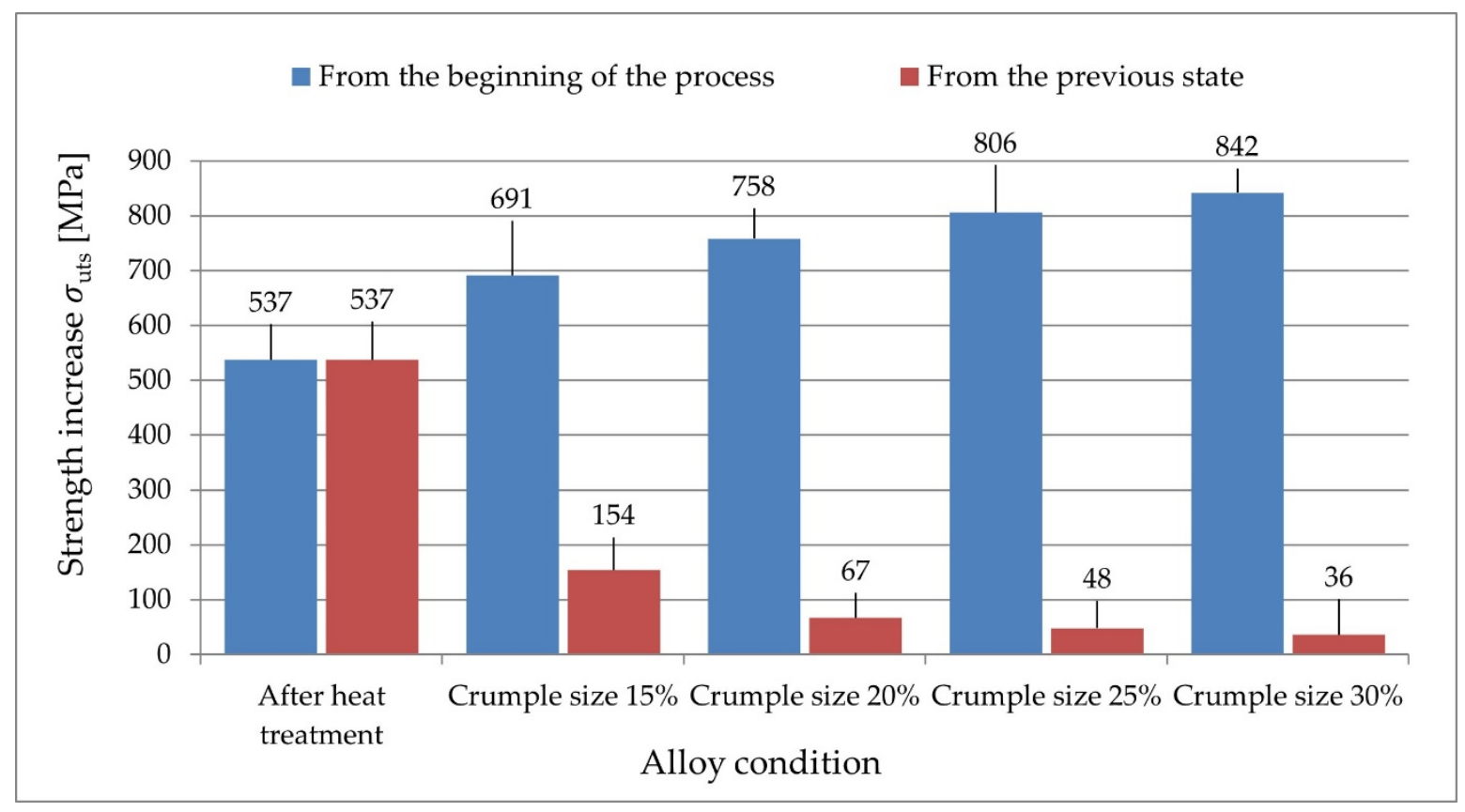

Figure 13. Increase in tensile strength for different WHA states.

The presented results show that the highest increase in strength occurs after heat treatment (increase by nearly $540 \mathrm{MPa}$ ) and after applying $15 \%$ of swaging deformation (increase by $690 \mathrm{MPa}$ from the sintering state and by $150 \mathrm{MPa}$ from the state after heat treatment). The higher deformation of cold swaging, the smaller the increase in tensile 
strength. With an increase in swaging deformation value from $15 \%$ to $20 \%$, the increase in strength is nearly $70 \mathrm{MPa}$. For the value of $25 \%$, the increase in strength is close to $50 \mathrm{MPa}$, and for the final value $30 \%$, the increase in strength is close to $40 \mathrm{MPa}$.

The total increase in strength that was obtained using heat-treatment and cold-work processes from the initial state (after sintering) to the final state (after 30\% deformation value) is over $840 \mathrm{MPa}$. The strengthening created during the plastic working process in the material causes a decrease in plasticity by $25 \%$ (from approximately $34 \%$ after heat treatment to $9 \%$ after working $30 \%$ ).

It should be noted that the applied heat treatment for WHA materials is a process that increases two opposing parameters: tensile strength $\sigma_{u t s}$, yield strength $\sigma_{y s}$, and elongation $\varepsilon$.

Rotary cold swaging is an incremental metalworking process for reducing the crosssectional area or otherwise changing the shape of rods, tubes, or wires by repeated radial blows with two or more dies. This article discusses the applicability of swaging and metal flow during swaging. Therefore, with a thorough insight into the material flow, it could be understood how to control it in order to achieve desired properties. Furthermore, by applying this method, different local cold hardening could be achieved by different total strain. It is necessary to make elongated subcaliber projectiles [16-21], which are classified as kinetic artillery (KE) projectiles characterized by high kinetic energy related to the area unit of the penetrator cross-section. The depth of penetration of kinetic artillery shells into metallic armored partitions depends on the following factors: the dynamic hardness and density of the shell materials (in this case the core).

The strengthening due to the cold swagging processing is evident and was expected. Due to intensive strain shear bands being formed in and across the grains, the diameter reduction and intensive straining resulted in thinning and shearing of the surface layer. The grain size was not evaluated as well, although due to the appearance of the shear bands, the fine microstructure can be expected.

Metallographic investigation revealed that microstructure after sintering and heat treatment consists of elongated grains with a moderate amount of fine recrystallized grains. The elongated grains are stretched during rotary swaging.

\section{Conclusions}

Based on the research, it can be concluded that:

The applied parameters of the sintering process make it possible to obtain a homogeneous porous material with the actual density equal to the theoretical density. This material has a two-phase microstructure, consisting of spherical tungsten grains evenly distributed in the matrix of the binding phase.

The applied parameters of heat treatment make it possible to change the properties of the WHA material from brittle to elastic-plastic, which are the basis for cold swagging.

The cold swaging deformations with reductions of $15-20 \%$ is the optimal value causing the highest increase in the strength properties of WHA material.

For the initial $15 \%$ of deformation value, the highest increase in WHA microhardness (both matrix and tungsten grains) can be observed.

An increase cold swaging deformations with reductions of $25 \%$ or $30 \%$ results in a poorly visible increase in tensile strength. Instead, it causes a significant reduction in plasticity.

For cold swaging deformations with reductions above $20 \%$, there was no increase in hardness using the Rockwell method.

The highest increase in WHA microhardness occurs for the initial 15\% of cold swaging deformations.

The use of heat and plastic treatments allows one to obtain a material with increased mechanical properties. The obtained strength and plastic values allow the use of this material for the production of modern kinetic penetrators. 
In the swaging process, the degree of the microhardening of the matrix in the material is higher than the degree of the tungsten grains.

Author Contributions: Conceptualization, P.S., Z.G. and O.G.; methodology, P.S., A.P. and Z.G.; validation, Z.G. and O.G.; formal analysis, P.S., Z.G. and O.G; investigation, P.S., Z.G. and A.P.; resources, P.S., Z.G. and O.G.; data curation, P.S., Z.G. and O.G.; writing-original draft preparation, P.S. and Z.G.; writing—review and editing, O.G.; visualization, O.G.; supervision, P.S., Z.G. and O.G.; project administration, P.S., Z.G. and O.G. All authors have read and agreed to the published version of the manuscript.

Funding: This research received no external funding and the APC was funded by the Warsaw University of Technology.

Institutional Review Board Statement: Not applicable.

Informed Consent Statement: Not applicable.

Data Availability Statement: The raw/processed data required to reproduce these findings cannot be shared at this time as the data also forms part of an ongoing study.

Conflicts of Interest: The authors declare no conflict of interest.

\section{References}

1. Gulbinowicz, Z.; Świercz, R.; Oniszczuk-Świercz, D. Influence of electrical parameters in electro discharge machining of tungsten heavy alloys on surface texture properties. In AIP Conference Proceedings; AIP Publishing LLC: Melville, NY, USA, 2018; p. 020007. [CrossRef]

2. Calvo, M.; Jakus, A.E.; Shah, R.N.; Spolenak, R.; Dunand, D.C. Microstructure and processing of 3D printed tungsten microlattices and infiltrated W-Cu composites. Adv. Eng. Mater. 2018, 20, 1800354. [CrossRef]

3. German, R.M. Liquid Phase Sintering; Plenum Press: New York, NY, USA, 1985.

4. German, R.M. Thermodynamics of sintering. In Sintering of Advanced Materials; Elsevier: Amsterdam, The Netherlands, 2010; pp. 3-32. [CrossRef]

5. Skoczylas, P.; Kaczorowski, M. The influence of cyclic sintering on the structure and mechanical properties of tungsten heavy alloy. Arch. Foundry Eng. 2016, 16, 131-136. [CrossRef]

6. Bagchi, T.P.; Ghosal, P.; Muraleedharan, K.; Sarma, B.; Maitra, N. Development of W-Ni-Co heavy alloy system. P/M Sci. Technol. Briefs 2000, 2, 21-24.

7. Gong, X.; Fan, J.L.; Ding, F.; Song, M.; Huang, B.Y. Effect of tungsten content on microstructure and quasi-static tensile fracture characteristics of rapidly hot-extruded W-Ni-Fe alloys. Int. J. Refract. Met. Hard Mater. 2012, 30, 71-77. [CrossRef]

8. Hyung, B.W.; Hee, H.M.; Pyo, K.E. Heat treatment behavior of tungsten heavy alloy. Solid State Phenom. 2006, 118, 35-40.

9. Das, J.; Appa Rao, G.; Pabi, S.K.; Sankaranarayana, M.; Sarma, B. Deformation behaviour of a newer tungsten heavy alloy. Mater. Sci. Eng. A 2011, 528, 6235-6247. [CrossRef]

10. Jacobs, J.; Haque, A.; Kulkarni, A.; Singh, J.; Matson, L. Microstructure of tungsten metal alloys produced by field assisted sintering technology (FAST). Int. J. Refract. Met. Hard Mater. 2019, 84, 104976. [CrossRef]

11. Shen, T.; Dai, Y.; Lee, Y. Microstructure and tensile properties of tungsten at elevated temperatures. J. Nucl. Mater. 2016, 468, 348-354. [CrossRef]

12. Demir, E.; Mirzayev, M.N.; Tuğrul, A.B.; Abdurakhimov, B.A.; Karaaslan, S.İ. An experimental study on microstructure of tungsten alloys. Surf. Rev. Lett. 2020, 27, 1950169. [CrossRef]

13. Şahin, Y. Recent progress in processing of tungsten heavy alloys. J. Powder Technol. 2014, 2014, 1-22. [CrossRef]

14. Das, J.; Appa Rao, G.; Pabi, S.K. Microstructure and mechanical properties of tungsten heavy alloys. Mater. Sci. Eng. A 2010, 527, 7841-7847. [CrossRef]

15. Kaczorowski, M.; Skoczylas, P.; Krzyńska, A.; Kaniewski, J. The strengthening of weight heavy alloys during heat treatment. Arch. Foundry Eng. 2012, 12, 75-80. [CrossRef]

16. Kaczorowski, M.; Skoczylas, P.; Nowak, W. The study of precipitation hardening of weight heavy alloys matrix. Arch. Foundry Eng. 2008, 8, 169-174.

17. Magier, M. The conception of the segmented kinetic energy penetrators for tank guns. J. Appl. Mech. 2010, 77, 051802. [CrossRef]

18. Motyl, K.; Magier, M.; Borkowski, J.; Zygmunt, B. Theoretical and experimental research of anti-tank kinetic penetrator ballistics. Bull. Pol. Acad. Sci. Tech. Sci. 2017, 65, 399-404. [CrossRef]

19. Kruszka, L.; Magier, M. Experimental investigations of visco-plastic properties of the aluminium and tungsten alloys used in KE projectiles. EPJ Web Conf. 2012, 26, 5005. [CrossRef]

20. Kruszka, L.; Magier, M.; Zielenkiewicz, M. Experimental analysis of visco-plastic properties of the aluminium and tungsten alloys by means of Hopkinson bars technique. AMM 2014, 566, 110-115. [CrossRef] 
21. Cheng, C.; Du, Z.; Chen, X.; Du, C.; Xu, L.; Wang, X. Oblique penetration of tungsten alloy rod to finite-thickness metal plate. Lat. Am. J. Solids Struct. 2019, 16, e233. [CrossRef]

22. Li, J.; Chen, X.; Huang, F. Ballistic performance of tungsten particle/metallic glass matrix composite long rod. Def. Technol. 2019, 15, 132-145. [CrossRef]

23. Senthilnathan, N.; Raja Annamalai, A.R.; Venkatachalam, G. Effect of cobalt addition on the morphology and mechanical properties of W-Ni-Cu-Co alloy. Emerg. Mater. Res. 2019, 8, 558-566. [CrossRef]

24. Goroch, O.; Gulbinowicz, Z.; Skoczylas, P.; Barcz, K.; Kaczorowski, M. Testing of the granulation process for the preparation of a mixture with the chemical composition of a heavy tungsten alloy. Probl. Mechatronics. Armament Aviat. Saf. Eng. 2020, 11, 43-56. [CrossRef]

25. Samadani, A.; Kudrolli, A. Angle of repose and segregation in cohesive granular matter. Phys. Rev. E 2001, 64, 051301. [CrossRef] [PubMed]

26. Skoczylas, P.; Gulbinowicz, Z.; Goroch, O.; Barcz, K.; Kaczorowski, M. Research into the production of tungsten heavy alloys with specific mechanical properties. Probl. Mechatronics. Armament Aviat. Saf. Eng. 2019, 10, 23-36. [CrossRef]

27. Kumari, A.; Prabhu, G.; Sankaranarayana, M.; Nandy, T.K. Effect of solution treatment temperature and cooling rate on the mechanical properties of tungsten heavy alloy. Mater. Sci. Eng. A 2017, 688, 225-236. [CrossRef]

28. Horubała, Z.; Ludyński, Z.; Nowak, W.; Nita, Z. Production of Heavy Alloys Based on Tungsten (Sposób Wytwarzania Stopów Ciężkich Na Bazie Wolframu-In Polish). PL Patent No. 194772, 26 April 2001.

29. Horubała, Z.; Ludyński, Z.; Nowak, W.; Nita, Z. Production of Heavy Alloys Based on Tungsten (Sposób Wytwarzania Stopów Ciężkich Na Bazie Wolframu-In Polish). PL Patent No. 194798, 26 April 2001.

30. Ren, C.; Fang, Z.Z.; Xu, L.; Ligda, J.P.; Paramore, J.D.; Butler, B.G. An investigation of the microstructure and ductility of Annealed cold-rolled tungsten. Acta Materialia 2019, 162, 202-213. [CrossRef]

31. Ludyński, Z. A Method of Producing Heavy Sinters (Sposób Wytwarzania Spieków Ciężkich—In Polish). PL Patent No. 171823, 6 October 1993.

32. Ravi Kiran, U.; Sambasiva Rao, A.; Sankaranarayana, M.; Nandy, T.K. Swaging and heat treatment studies on sintered 90W-6Ni2Fe-2Co tungsten heavy alloy. Int. J. Refract. Met. Hard Mater. 2012, 33, 113-121. [CrossRef]

33. Ravi Kiran, U.; Panchal, A.; Prem Kumar, M.; Sankaranarayana, M.; Nageswara Rao, G.V.S.; Nandy, T.K. Refractory metal alloying: A new method for improving mechanical properties of tungsten heavy alloys. J. Alloy. Compd. 2017, 709, 609-619. [CrossRef]

34. Ravi Kiran, U.; Venkat, S.; Rishikesh, B.; Iyer, V.K.; Sankaranarayana, M.; Nandy, T.K. Effect of tungsten content on microstructure and mechanical properties of swaged tungsten heavy alloys. Mater. Sci. Eng. A 2013, 582, 389-396. [CrossRef]

35. Katavić, B.; Odanović, Z.; Burzić, M. Investigation of the rotary swaging and heat treatment on the behavior of W- and $\gamma$-phases in PM 92.5W-5Ni-2.5Fe-0.26Co heavy alloy. Mater. Sci. Eng. A 2008, 492, 337-345. [CrossRef]

36. Kumari, A.; Sankaranarayana, M.; Nandy, T.K. On structure property correlation in high strength tungsten heavy alloys. Int. J. Refract. Met. Hard Mater. 2017, 67, 18-31. [CrossRef]

37. Panchal, A.; Nandy, T.K. Effect of composition, heat treatment and deformation on mechanical properties of tungsten heavy alloys. Mater. Sci. Eng. A 2018, 733, 374-384. [CrossRef]

38. Skoczylas, P.; Gulbinowicz, Z.; Goroch, O. Microstructure and properties of tungsten heavy alloy connections formed during sintering with the participation of the liquid phase. Materials 2020, 13, 4965. [CrossRef] [PubMed]

39. Katavic, B.; Nikacevic, M.; Odanovic, Z. Effect of cold swaging and heat treatment on properties of the P/M 91W-6Ni-3Co heavy alloy. Sci. Sinter. 2008, 40, 319-331. [CrossRef]

40. Humail, I.S.; Akhtar, F.; Askari, S.J.; Tufail, M.; Qu, X. Tensile behavior change depending on the varying tungsten content of W-Ni-Fe alloys. Int. J. Refract. Met. Hard Mater. 2007, 25, 380-385. [CrossRef] 